\title{
Avaliação da glicemia de ovelhas Dorper aos 140 dias de gestação, momento do parto, 24 e 48 horas pós-parto: comparação entre gestação única e gemelar - resultados parciais
}

Bianca Paola Santarosa $a^{[]^{*}}$, Gabriela Nascimento Dantas ${ }^{[a]}$, Danilo Otávio Laurenti Ferreira ${ }^{[b]}$, Yuri Karen Sinzato ${ }^{[c]}$, Débora Cristina Damasceno ${ }^{[c]}$, Andreza Amaral da Silva ${ }^{[d]}$, Roberto Calderon Gonçalves ${ }^{[a]}$

\footnotetext{
[a] Departamento de Clínica Veterinária, Faculdade de Medicina Veterinária e Zootecnia, Universidade Estadual Paulista (UNESP), Botucatu, SP, Brasil

[b] Secretaria da Agricultura e Abastecimento do Estado de São Paulo, Coordenadoria de Assistência Técnica Integral (CATI), Casa da Agricultura de Agudos, Agudos, SP, Brasil

[c] Laboratório Experimental de Ginecologia e Obstetrícia, Faculdade de Ciências Médicas e Biológicas, Universidade Estadual Paulista (UNESP), Botucatu, SP, Brasil

[d] Departamento de Medicina e Cirurgia, Universidade Federal Rural do Rio de Janeiro (UFRRJ), Seropédica, RJ, Brasil
}

*Autor correspondente

e-mail: biancasantarosavet@gmail.com

\section{Resumo}

A toxemia da prenhez (TP) ocorre no terço final da gestação de ovelhas com fetos múltiplos ou muito grandes e está associada à deficiência energética. A glicose é um dos metabólitos importantes no monitoramento do status energético durante gestação, especialmente no periparto. Assim, o objetivo deste trabalho foi comparar a glicemia de ovelhas adultas, prenhes de feto único e gemelar, criadas sob manejo semi-intensivo, a fim de verificar alterações metabólicas no periparto. Utilizaram-se 30 ovelhas da raça Dorper, vazias e hígidas, de dois a cinco anos de idade, peso médio de $60 \mathrm{~kg}$. Os ovinos foram soltos pela manhã e ficaram a pasto durante o dia (capim Vaquero ${ }^{\circledR}$ - Cynodon dactylon - 13,48\% PB). No final da tarde, os animais foram presos em baias coletivas, onde foram alimentados com 0,5 kg/animal de ração para manutenção (20,85\% PB, $3.871 \mathrm{cal} / \mathrm{g})$ e 1,0 kg/animal de silagem de milho (8,28\% PB). Constituíram-se dois grupos experimentais: Grupo I (GI) - 15 ovelhas, com gestação de feto único; Grupo II (GII) - 15 ovelhas, com gestação gemelar. Todas as ovelhas foram submetidas ao protocolo de inseminação artificial em tempo fixo pela técnica de laparoscopia. Os momentos experimentais deste estudo foram definidos como: MG140 - 140 dias de gestação, MP - momento do parto, MPP1 - 24 horas após o parto, MPP2 - 48 horas após o parto. Colheu-se $1 \mathrm{~mL}$ de sangue por punção da veia jugular, em seringa de polietileno previamente heparinizada, acoplada à agulha de 30x8mm. Foi realizada, imediatamente após a colheita, a mensuração da glicose pelo 
uso do cartucho CHEM8+ em aparelho portátil de hemogasometria (I-STAT ${ }^{\circledR}$, Abbott Laboratories, Illinois, EUA). Para análise estatística, utilizou-se o programa Instat 3. Para as comparações entre os grupos foi usado o Teste $\mathrm{T}$ e, entre os momentos, foi empregado o teste de comparações múltiplas de Tukey $(\mathrm{P}<0,05)$. 0 período gestacional das ovelhas variou de 136 a 145 dias. Nenhuma ovelha apresentou sintomatologia clínica de TP e não houve diferença estatística entre os grupos; porém, ao longo dos momentos, existiu diferença em ambos os grupos. Os resultados dos grupos no momento MP (GI: $166,18 \pm 4,80 \mathrm{mg} / \mathrm{dL}$; GII: $149,13 \pm 71,01 \mathrm{mg} / \mathrm{dL}$ ) diferiram estatisticamente do MG140 (GI: 60,93 \pm 5,47 mg/dL; GII: 60,73 \pm 4,80 mg/dL), MP24 (GI: 81,33 \pm $43,81 \mathrm{mg} / \mathrm{dL} ; \mathrm{GII}: 70,80 \pm 15,78 \mathrm{mg} / \mathrm{dL}$ ) e MP48 (GI: 64,13 $\pm 11,84 \mathrm{mg} / \mathrm{dL} ; \mathrm{GII}: 68,06 \pm 18,85 \mathrm{mg} / \mathrm{dL}$ ). A partir desses resultados, foi possível observar que as ovelhas, de ambos os grupos, apresentaram hiperglicemia no momento do parto (MP) em relação aos demais momentos de análise e ao padrão de normalidade da espécie (50 a $80 \mathrm{mg} / \mathrm{dL}$ ). Portanto, o aumento nas concentrações de glicose observado no parto simples e gemelar ocorreu como consequência da liberação de glicocorticoides como sinalizador do parto em ovinos.

Agradecimentos: Fundação de Amparo à Pesquisa do Estado de São Paulo (FAPESP) - Processo FAPESP 2015/08714-8 e Fazenda Monjolão - Cabanha Araí \& Zumbi - Pardinho/SP. 